\title{
Desenvolvimento de um modelo para análise da acumulação de capacidades tecnológicas na indústria da construção civil: subsetor de edificações
}

\author{
Developing a model to analyze technological capabilities \\ accumulation in the construction industry: building sector
}

\begin{tabular}{|c|c|}
\hline & $\begin{array}{l}\text { Renata Furtado Gradvohl } \\
\text { Ana Augusta Ferreira de Freitas } \\
\text { Luiz Fernando Mahlmann Heineck }\end{array}$ \\
\hline & 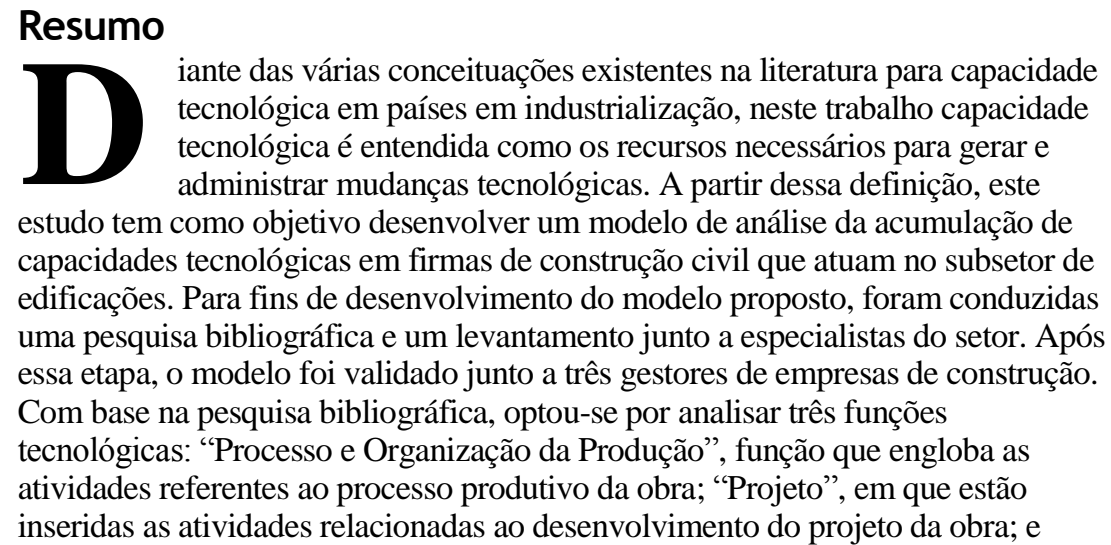 \\
\hline $\begin{array}{r}\text { Renata Furtado Gradvohl } \\
\text { Centro de Estudos Sociais } \\
\text { Aplicados } \\
\text { Universidade Estadual do Ceará } \\
\text { Av. Paranjana, 1700, Itaperi }\end{array}$ & $\begin{array}{l}\text { "Equipamentos", que contém as atividades ligadas ao uso, aprimoramento e } \\
\text { desenho dos equipamentos usados pela companhia no processo de produção. O } \\
\text { modelo final pode ser utilizado para exame e gestão do processo de } \\
\text { desenvolvimento industrial de firmas desse setor. }\end{array}$ \\
\hline $\begin{array}{r}\text { Fortaleza - CE - Brasil } \\
\text { CEP 60740-000 } \\
\text { Tel.: (85) 3101-9937 }\end{array}$ & Palavras-chave: Modelo. Capacidade tecnológica. Construção civil. \\
\hline renatagradvohl@gmail.com & Abstract \\
\hline $\begin{array}{r}\text { Ana Augusta Ferreira de } \\
\text { Freitas } \\
\text { Centro de Estudos Sociais } \\
\text { Aplicados }\end{array}$ & $\begin{array}{l}\text { As there are several different concepts in the literature regarding technological } \\
\text { capabilities in developing countries, in this study technological capability was } \\
\text { defined as the resources needed to generate and manage technological change. } \\
\text { Based on that definition, the aim of this study is to develop a model to analyze } \\
\text { technological capabilities accumulation in construction firms working in the }\end{array}$ \\
\hline $\begin{array}{l}\text { Universidade Estadual do Ceará } \\
\text { E-mail: freitas8@terra.com.br }\end{array}$ & $\begin{array}{l}\text { building sector. For the purpose of developing the proposed model, a literature } \\
\text { review and a survey with industry experts were conducted. After this stage, the } \\
\text { model was validated in three construction company managers. Based on the }\end{array}$ \\
\hline $\begin{array}{r}\text { Luiz Fernando Mahlmann } \\
\text { Heineck } \\
\text { Centro de Estudos Sociais } \\
\text { Aplicados }\end{array}$ & $\begin{array}{l}\text { literature review, the choice was made to analyse three technological functions: } \\
\text { 'Process and Organization of Production', a function that includes activities } \\
\text { related to the production process; 'Design', a function that includes activities }\end{array}$ \\
\hline Universidade Estadual do Ceará & related to the development of design; and 'Equipment', which consists of activities \\
\hline $\begin{array}{r}\text { E-mail: } \\
\text { heineck@pesquisador.cnpq.br }\end{array}$ & $\begin{array}{l}\text { related to the use, improvement and design of new design tools and machines used } \\
\text { by the company in the production process. The final model can be used for } \\
\text { examining and managing the industrial development process of firms from this }\end{array}$ \\
\hline ecebido em 02/09/2010 & \\
\hline & eywords: Model. Technological capability. Construction industry. \\
\hline
\end{tabular}

Ambiente Construído, Porto Alegre, v. 11, n. 1, p. 41-51, jan./mar. 2011. 


\section{Introdução}

A partir da década de 1970, estudiosos da área de inovação (KIM, 1980; LALL, 1992; BELL, 1984) começaram a discutir a importância de compreender a mudança tecnológica em países em desenvolvimento a partir de uma concepção mais ampla do próprio conceito de tecnologia, inicialmente concebido como um bem de capital. O conceito de capacidade tecnológica, entendido como os recursos necessários para gerar e gerenciar mudança tecnológica (BELL; PAVITT, 1995), é utilizado como fio condutor de uma série de trabalhos que buscam compreender a evolução tecnológica das firmas situadas em países em desenvolvimento. Notadamente se reconhecem os estudos sobre inovação em clusters (CANIËLS; ROMIJN, 2003), inovação em cadeias de valor globais (SCHMITZ, 2007) e inovação em redes de conhecimento/aprendizagem (BELL; ALBU, 1999). Para a avaliação da evolução da capacidade tecnológica das empresas, tais estudos desenvolvem métricas de análise apropriadas ao setor e ao contexto das empresas. Essa é também a preocupação principal deste estudo, que tem como objetivo desenvolver um modelo de análise da acumulação de capacidades tecnológicas em firmas de construção civil que atuam no subsetor de edificações.

A escolha pelo setor apóia-se na discussão feita por alguns autores sobre a necessidade de ampliar os estudos na área de inovação no setor da construção civil (REICHSTEIN; SALTER; GANN, 2005) e, de maneira específica, nas empresas, lócus onde a inovação ocorre de fato. O fato de as pesquisas sobre inovação colocarem o foco, em sua maior parte, nas indústrias, nos negócios orientados por ciência e tecnologia e nas firmas intensivas em conhecimento promove uma atenção maior na base de conhecimento das firmas e na forma como estas podem aumentar suas capacidades inovativas por meio de investimentos em P\&D, por exemplo. Tais estudos são parciais na explicação das firmas low-tech, situadas em setores tradicionais da economia. Vale ainda ressaltar que o presente trabalho trata de um subsetor da indústria da construção, que é o de edificações. Ao contrário da indústria de construção pesada (pontes, portos e grandes obras arquitetônicas), o subsetor de edificações se qualifica entre os setores tradicionais da economia, com baixa intensidade tecnológica.

Numa perspectiva intrafirmas, estudos que tenham como base o desenvolvimento de modelos que orientem a análise da trajetória seguida por empresas no acúmulo de suas capacidades têm o potencial de embasar decisões gerenciais focadas na inovação. Em nível macro, políticas públicas podem ser desenvolvidas a partir da análise da forma e da velocidade de acumulação de capacidades na área de inovação das empresas de determinado setor da economia.

\section{Fundamentação teórica}

A seção de fundamentação teórica encontra-se dividida em duas subseções:

(a) a primeira discute a evolução histórica do
conceito de capacidades tecnológicas e

(b) a segunda revisa as principais abordagens da inovação na construção civil.

\section{Capacidades tecnológicas: conceitos e formas de mensuração}

Diante das várias conceituações existentes para o conceito de capacidade tecnológica na literatura sobre países em industrialização, neste trabalho é utilizada a definição de Bell e Pavitt (1995), para os quais capacidade tecnológica é definida como os recursos necessários para gerar e administrar mudanças tecnológicas, sendo esses recursos incorporados tanto em indivíduos, por meio de suas aptidões, conhecimentos e experiências, quanto nos sistemas organizacionais. A capacidade tecnológica é, então, um estoque organizacional incorporado nos seguintes componentes:

(a) sistema físico: refere-se, basicamente, à parte técnica da tecnologia;

(b) pessoas: é o capital humano da empresa;

(c) sistema organizacional: conhecimento incorporado nas rotinas organizacionais; $\mathrm{e}$

(d) produtos e serviços.

Não valorizar esses quatro componentes em conjunto conduz à adoção de uma perspectiva limitada da capacidade tecnológica, o que pode acarretar resultados desfavoráveis na implementação de estratégias de inovação nas empresas (FIGUEIREDO, 2005).

O estudo de Lall (1992) apresenta uma estrutura analítica com a função de mensurar o nível de acumulação de capacidades tecnológicas em empresas. O autor adotou como estratégia metodológica a mensuração das capacidades tecnológicas a partir do exame de um conjunto de atividades, estruturado por funções tecnológicas, que tais empresas são capazes de exercer, de forma autônoma, ao longo do tempo. A acumulação de capacidades processa-se a partir das categorias mais simples às mais complexas, que caracterizam 
os níveis, que variam de "básico" a "líder mundial". A maneira (direção) e a velocidade com que as empresas acumulam capacidades é base para a avaliação de sua performance inovadora. Além disso, é importante ressaltar a importância de estudos como este, que consideram medidas alternativas para análise das capacidades inovadoras, além dos gastos com P\&D e patentes, inadequadas para refletir a inovação em economias emergentes.

Posteriormente, Bell e Pavitt (1995) aprofundaram o estudo sobre esse modelo inicial, incorporando a ele uma diferenciação entre os níveis tecnológicos, de acordo com a capacidade para usar a tecnologia existente e a capacidade para gerar e gerir mudanças tecnológicas. Os níveis de capacidades tecnológicas são divididos em rotineiros e inovadores. $\mathrm{O}$ primeiro engloba as atividades relativas à capacidade de utilizar a tecnologia, o conhecimento e os mecanismos organizacionais já existentes, enquanto o segundo é composto de atividades que são desempenhadas com a finalidade de gerar mudanças tecnológicas, assim como aperfeiçoar as já existentes (BELL; PAVITT, 1995).

A partir desses estudos, Figueiredo (2001) realizou uma adaptação dessa estrutura analítica para ser aplicada, especificamente em empresas da indústria do aço. Posteriormente, outros estudos utilizam também esse modelo, adaptando-o para outros setores, tais como o de Ben (2001), que realizou um estudo na indústria moveleira, o de Büttenbender (2001), na indústria metalomecânica, o de Costa (2002), na indústria de injeção plástica, o de Garcia (2006), na indústria de celulose e papel, e o de Brito (2008), no setor de tecnologia da informação e comunicação (TIC). Utilizando essa mesma estrutura de Lall (1992), este artigo realiza uma adaptação para o subsetor de edificações da construção civil, que é apresentada posteriormente.

Além do modelo proposto por Lall (1992), outros autores sugerem estruturas para mensuração do desenvolvimento tecnológico. Rush, Bessant e Hobday (2007), por exemplo, realizaram um estudo com o intuito de auxiliar os agentes políticos a segmentar os diferentes tipos de empresas de acordo com o nível de desenvolvimento de sua capacidade inovativa. O modelo proposto por esses autores se configura como uma ferramenta de avaliação da capacidade tecnológica, onde os decisores políticos podem identificar os pontos fortes e fracos das empresas, para, assim, conceberem políticas que sejam orientadas e alinhadas com objetivos políticos que visem aumentar a capacidade tecnológica nas empresas. Apesar de mais recente do que o modelo de Lall (1992), o de Rush, Bessant e Hobday (2007) não foi considerado adequado, já que não distingue as diferenças entre os setores e as diferentes funções que fazem parte deles.

Para o desenvolvimento do modelo de Lall (1992), adaptado à construção civil e, de maneira específica, ao subsetor de edificações, é essencial o estudo do setor e a revisão das pesquisas que tratam de inovação na construção civil como forma de análise e escolha das funções tecnológicas a serem estudadas.

\section{Inovação tecnológica na construção civil}

A performance na indústria da construção em termos de produtividade, qualidade e funcionalidade do produto tem sido baixa quando comparada a outras indústrias, situação essa que tem sido explicada pela baixa taxa de inovação. As causas desse baixo índice de inovação, por outro lado, já foram investigadas e, entre outras questões, os fatores institucionais, as peculiaridades do setor e os modelos teóricos subjacentes têm sido apontados como determinantes dessa situação (KOSKELA; VRIJHOEF, 2001). Vargas (1979) foi um dos pioneiros a tratar o tema, levantando questões estruturais do setor, associadas ao funcionamento da economia capitalista, de forma geral. O fato de haver maiores ganhos com a comercialização do que com a produção do bem em si não incentiva as inovações tecnológicas, segundo o autor.

No que se refere à influência do Estado para inovação nas empresas de construção, as políticas para construção caracterizaram-se, ao longo do tempo, pela montagem de um aparato financeiro e institucional que visavam não propriamente à construção, mas à criação de empregos e à distribuição habitacional. Assim, o Estado adotou um sistema rígido, impondo um único padrão tecnológico (AMORIM, 1992), a partir de critérios pouco claros. Mesmo em programas habitacionais atuais, que prometem consequências na qualidade de vida da população, assiste-se, sim, à repetição dos antigos padrões $\mathrm{BNH}$, fato criticado por autores como Valladares (1983).

Sobre esse atraso tecnológico, Ball (1999) afirma que as empresas de construção civil podem ser classificadas como conservadoras, aversas ao risco, com pouco investimento em $\mathrm{P} \& \mathrm{D}$, com poucas operações de rotina e dependentes dos fornecedores para o desenvolvimento de novas tecnologias. Ainda sobre as barreiras, Nam e Tatum (1988) identificam uma série de características do produto da construção e do processo de produção que limitam a inovatividade, entre elas a não mobilidade da produção, a 
complexidade do processo e a durabilidade do produto. Sendo assim, descrevem a construção como um sistema fechado, em que é difícil se desvencilhar das características da indústria para inovar. Bayer e Gann (2006) apresentam outra explicação para as barreiras à inovação enfrentadas por indústrias da construção, ao situá-las como organizações baseadas em projetos. Segundo eles em organizações dessa natureza, o processo de aprendizagem é descontínuo e, por isso, elas potencialmente são mais limitadas a mudar de curso e a adquirir novas ou mais avançadas capacidades do que outras empresas.

No entanto, essa visão não é consistente entre os pesquisadores da área. Segundo Slaughter (1993, 1999), embora exista uma percepção generalizada de que não existe inovação na construção, ela ocorre, e de forma consistente, em todos os setores dessa indústria, sendo as fontes mais prováveis de inovação as pessoas que trabalham no canteiro de obra. Ainda segundo a autora, as inovações dos construtores são diferentes daquelas originadas nos fornecedores, sendo as primeiras mais integradas ao sistema de construção. É possível afirmar que os usuários de tecnologia na indústria da construção são fontes importantes de inovação tecnológica, e o desenho dos produtos deveria incorporar a flexibilidade necessária para adaptações às necessidades desses usuários nos canteiros de obra. Outro importante ator nesse processo são as pequenas firmas de construção intensivas em conhecimento que prestam serviços de consultoria (LU; SEXTON, 2006).

Igualmente importante é que os dirigentes dessas empresas reconheçam as possibilidades de inovação e planejem suas atividades com base em suas condições estruturais (SLAUGHTER, 1999). Ainda sobre o papel dos gestores, Hartmann (2006) destaca a importância de eles defenderem claramente ideias inovadoras, tomarem decisões estratégicas planejadas sobre os rumos das medidas inovadoras que serão desempenhadas, assim como favorecerem um processo inovador com apoio metodológico e hierarquizado.

Finalmente, torna-se mister reconhecer o papel dos institutos de pesquisas, e de maneira específica das Univesidades, como lembram Aouad, Ozorhon e Abbott (2010). Pesquisando a construção civil na Austrália, Keast e Hampson (2007) afirmam que a perspectiva de crescimento desse setor encontra-se em sua capacidade em desenvolver inovações, que convencionalmente são promovidas por instituições especializadas em pesquisas por meio de financiamento público, com o apoio de instituições de ensino superior e de empresas que fazem parte da própria indústria. Contudo, os mesmos autores ressaltam que esses modelos convencionais de desenvolvimento de inovações têm-se tornado insuficientes diante da necessidade de inovações em uma maior escala e sugerem, diante disso, que as redes interorganizacionais podem facilitar o fluxo acelerado de informações e de recursos, com o intuito de difundir as inovações no setor. A associação entre empresas é igualmente sugerida por Ruikar, Koskela e Sexton (2009) através das comunidades de prática, caracterizadas por eles como importante lócus para compartilhamento de conhecimento.

Em síntese, Reichstein, Salter e Gann (2005) mostram que, embora localizadas em um setor considerado como de relativo atraso tecnológico, firmas de construção civil têm conseguido sair desse contexto por meio do relacionamento com consumidores (inovação no produto) e fornecedores (inovação no processo), e de uma orientação para mercados mais amplos - além dos locais (inovação no produto). Os autores ainda mostram que firmas maiores são mais prováveis de inovar no processo do que firmas de menor porte, mas não mais prováveis de inovar no produto. As despesas com P\&D têm pouca ou nenhuma importância no desenvolvimento de inovação no produto e no processo de construção. Os autores ainda acharam evidências de que a absorção de conhecimento sobre regulações não aumenta as chances de a firma inovar. Os resultados do estudo dos autores podem ser sintetizados da seguinte forma: inovadores de produto na construção são firmas que confiam em seus clientes e na universidade como fontes de ideias para inovação, têm orientação nacional ou internacional, investem em treinamentos e têm acordos formais de cooperação. Inovadores em processos na construção tendem a ser empresas maiores, que confiam em seus fornecedores, gastam recursos em treinamento e têm parcerias de cooperação com organizações externas.

Nesse mesmo sentido, e ainda reconhecendo barreiras à inovação em organizações de projeto, como é o caso das firmas de construção, Bayer e Gann (2006) apontam possibilidades de acumulação de capacidades tecnológicas. Os autores desenvolveram uma abordagem para o gerenciamento da inovação que relaciona a aquisição de contratos de trabalho (que engloba questões como reputação, mudança de demanda), a execução do projeto (que engloba questões de complexidade, alocação de tempo e recursos) e a construção de capacidade e inovação (que engloba questões de pressões de tempo, diversidade de projetos, oportunidades de aprendizado e outras barreiras à inovação). Segundo eles, capacidades mais desenvolvidas permitem à organização implementar soluções de problemas de forma mais 
inovadora, o que resulta em acumulação de capacidade. Da mesma forma, a acumulação de capacidades permite aumentar o leque de possibilidades de aquisição de novos trabalhos (novos projetos), diferentes daqueles anteriormente conduzidos pela firma.

Finalmente, é importante revisar autores que discutem onde a inovação é encontrada no setor da construção civil. Cardoso (1996) afirma que, no setor de construção civil, a principal possibilidade de modernização encontra-se na busca por novas maneiras de racionalização dos processos produtivos tradicionais, tendo sido essa questão citada também por Barros, Sabbatini e Franco (1996) e Aro e Amorim (2004). A mudança tecnológica na construção, segundo Castro (1999), em muitos casos ocorre a partir da mudança dos produtos de componentes e processos a eles associados. Uma área tradicionalmente não apropriada pelos projetistas e arquitetos é a do produto componente para a construção. No que se refere à inovação em processos produtivos, alguns estudos (BERNARDES, 2003; HEINECK; MACHADO, 2001) apontam para os conhecimentos advindos dos princípios da Lean Construction (construção enxuta), uma filosofia de produção que se baseia no Modelo Toyota de Produção, específica para a realidade do setor da construção civil.

Ainda sobre esse assunto, Aro e Amorim (2004) afirmam que a introdução e difusão de inovações tecnológicas na construção civil são dificultadas pelos profissionais envolvidos no setor, diante do receio destes em mudar seu estado atual e assumir os riscos provenientes das mudanças. Aro e Amorim (2004) prosseguem afirmando que esse receio à mudança, juntamente com o fato de os projetos necessitarem de uma visão multidisciplinar, como também devido à dependência do setor em relação à pesquisa de novos materiais e equipamentos, propicia que a construção civil não se modernize com a velocidade de outros setores produtivos. Contudo, esses mesmos autores defendem que os profissionais projetistas possuem meios de acarretar inovações tecnológicas para empresas do setor, podendo estes equacionar melhor as questões dos custos e da diminuição dos desperdícios, como também inserir em seus projetos novos materiais oferecidos pela cadeia de fornecedores, contribuindo para a racionalização do processo e para a melhoria da qualidade do produto final. As argumentações apresentadas nesta subseção serviram de base para reforçar a escolha pelo estudo das funções, pelo entendimento gerado de que nelas é possível o surgimento de inovações no setor da construção civil:
(a) processo e organização da produção;
(b) projeto; e
(c) equipamentos.

\section{Metodologia}

Para a utilização neste trabalho do modelo de mensuração de capacidades tecnológicas proposto por Lall (1992), foi necessária a realização de um processo de adaptação para o setor. Uma primeira etapa consistiu da definição da quantidade de níveis de complexidade, para cada função tecnológica, juntamente com a realização da conceituação de cada um deles. A partir disso, foram definidas as atividades que englobariam cada um dos diferentes níveis de capacidades tecnológicas. Na Figura 1, é possível verificar as três etapas gerais que foram percorridas no decorrer desse processo.

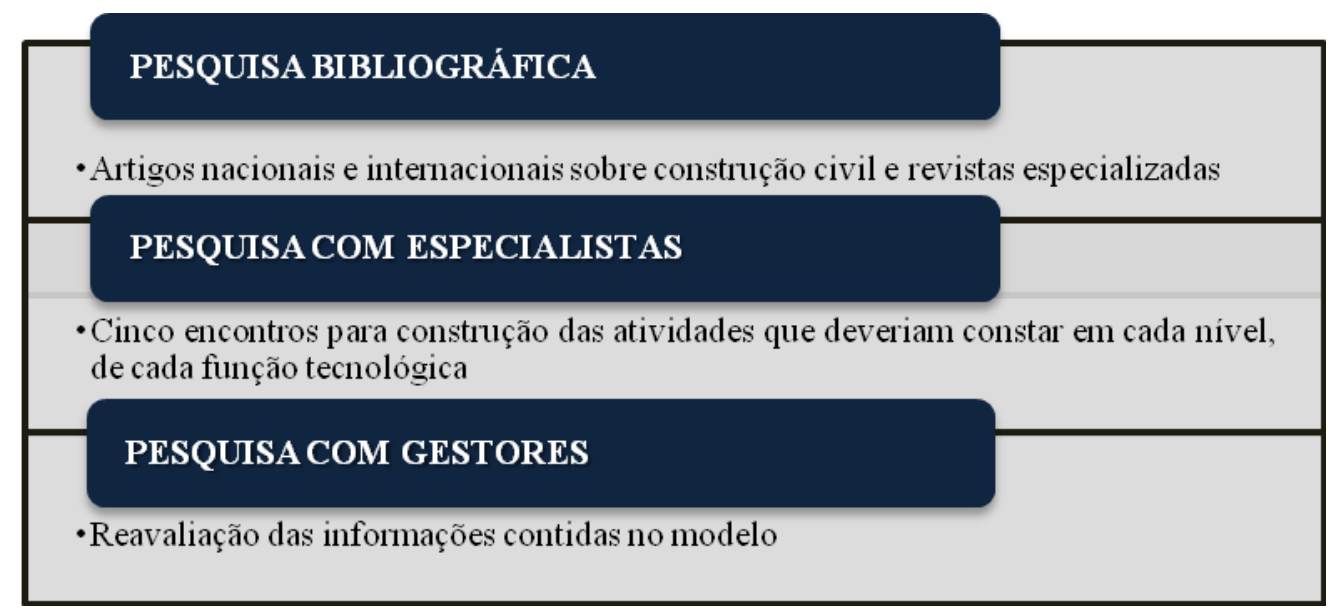

Figura 1 - Processo de adaptação do Modelo de Mensuração de Competências Tecnológicas 
A primeira etapa consistiu de uma pesquisa bibliográfica, fundamentalmente em artigos nacionais e internacionais e em revistas que discutem temas relacionados à inovação tecnológica na construção civil. Uma importante fonte de consulta foi a Revista Techné dos últimos cinco anos, que alcança em 2010 o número 160, tendo seu primeiro número sido lançado em 1992. O levantamento feito indicou que é possível extrair cerca de dez inovações tecnológicas de cada número, sinalizando a existência de cerca de 1.600 inovações no total e uma média de cerca de 100 inovações por ano, julgadas de atratividade como objeto de divulgação jornalística. Essas inovações foram julgadas pelos autores e apreciadas, quando pertinente, pelos especialistas que participaram da segunda etapa da pesquisa.

Além da pesquisa bibliográfica, outra etapa de fundamental importância nesse processo de adaptação foram as pesquisas realizadas com dois especialistas do setor da construção civil, ambos doutores na área. $\mathrm{O}$ primeiro, $\mathrm{PhD}$ em engenharia civil, milita na área há cerca de 33 anos, tendo acompanhado as atividades de construção civil de forma acadêmica desde o início dos primeiros mestrados na área de construção civil, nos meados da década de 1970. Atuou em quatro mestrados diferentes nas Regiões Sul e Nordeste do país. A segunda especialista também acompanhou os desdobramentos nas regiões Nordeste e Sul do país, tendo realizado seu doutorado na área na Universidade de Berkeley, atuando atualmente como professora na Universidade de San Diego. No total, foram realizados cinco encontros, quatro com um primeiro especialista e um encontro com um segundo especialista, perfazendo cerca de vinte horas de conversas. Todos os encontros foram gravados em áudio e vídeo, com a permissão dos especialistas, a fim de possibilitar averiguações posteriores.

No encontro inicial, apresentou-se ao primeiro especialista a estrutura do modelo de mensuração de capacidades tecnológicas, para que ele entendesse como o processo de adaptação deveria ser desenvolvido. Nessa etapa, as três funções tecnológicas abordadas neste estudo (Processo e Organização da Produção, Projeto e Equipamentos), já definidas com base na revisão da literatura, foram apresentadas. A partir de então, as conversas desse primeiro encontro foram conduzidas para a construção das atividades que deveriam constar na função Processo e Organização da Produção. Essas atividades foram classificadas pelo especialista pelo grau de dificuldade e inovação, tendo sido enquadradas, no primeiro momento, em sete níveis de complexidade.
No segundo encontro, realizado também com o primeiro especialista, foram definidas as atividades que deveriam constar nas outras duas funções em estudo (Projeto e Equipamentos). Ao final, as atividades referentes a essas funções foram inseridas em quatro níveis de complexidade. No terceiro encontro, realizado com o segundo especialista, apresentou-se a estrutura inicial do modelo em questão, com base nas informações obtidas nos dois encontros iniciais com o primeiro especialista. Novas atividades foram incorporadas ao modelo, e outras foram reposicionadas em relação a seu nível de complexidade. A partir daí voltou-se ao primeiro especialista, com o seguinte objetivo: verificar as modificações propostas pelo segundo especialista. Desse encontro, as atividades referentes às três funções passaram a ser apresentadas em cinco níveis de complexidade.

Finalmente, um quinto e último encontro foi realizado com o primeiro especialista para avaliar se as atividades presentes no modelo estavam coerentes com os conceitos dos níveis. Para esse último objetivo, contou-se também com o apoio informal de um especialista da Fundação Getúlio Vargas (EBAPE/RJ), que trabalha como pesquisador no grupo de Gestão da Aprendizagem Tecnológica e Inovação Industrial no Brasil. Dessa última reunião resultaram ainda modificações na forma de escrita das atividades para expressar o caráter rotineiro e/ou inovador dos diversos níveis de complexidade tecnológica. Conforme se pode observar, essa segunda etapa da pesquisa foi caracterizada por um movimento pendular de idas e vindas para ajuste do modelo, o que deu aos autores confiança no que diz respeito à contemporização de diferentes visões, ainda que se reconheça a limitação metodológica de se trabalhar com apenas dois especialistas.

Uma última etapa consistiu na validação desse modelo com três gestores de empresas de construção civil, atualizados das últimas inovações do setor através da participação em feiras e eventos nacionais e internacionais. Uma explicação inicial sobre a concepção geral do modelo incluiu o significado das funções tecnológicas e dos níveis. $\mathrm{Na}$ ocasião poucos ajustes foram feitos, e a intervenção ocorreu principalmente na realocação de algumas atividades que eles consideravam ser de menor complexidade, como a utilização de sistemas de gestão de resíduos. Na seção seguinte, apresenta-se o modelo de mensuração de competências tecnológicas adaptado ao subsetor de edificações da construção civil, englobando as três funções tecnológicas abordadas na pesquisa empírica deste trabalho, que são: 
(a) processo e organização da produção;

(b) projeto; $\mathrm{e}$

(c) equipamentos.

Cada uma dessas funções é analisada a partir de atividades que estão inseridas em cinco níveis tecnológicos:
(a) rotineiro básico;
(b) rotineiro avançado;
(c) inovador básico;
(d) inovador intermediário; e
(e) inovador avançado.

\section{Desenvolvimento do modelo de acumulação de competências tecnológicas}

No processo de adaptação do modelo de Lall (1992) de mensuração de capacidades tecnológicas para o subsetor de edificações da construção civil, optou-se por analisar três funções tecnológicas (Quadro 1), que são definidas a seguir. A função Processo e Organização da Produção engloba as atividades referentes a todo o processo produtivo da obra, que inclui movimento de terra, fundação, infraestrutura de concreto, alvenaria, tubulação, revestimento (parede, teto e piso), instalações de fios, impermeabilização, acabamentos (ex.: tomadas, disjuntores), etc. As inovações, nesta função, podem ocorrer em qualquer área ligada à produção, inclusive no controle, no planejamento e na logística da construção.

$\mathrm{Na}$ função Projeto estão inseridas as atividades relacionadas ao desenvolvimento do projeto da obra. As inovações, nesta função, podem ocorrer de diversas maneiras, desde a forma como o projeto é concebido até a forma como ele é gerenciado. Em níveis mais avançados, os projetos englobam soluções para construção de produtos de maior complexidade e envolvem a participação de um número maior de projetistas em funções especializadas. A função Equipamentos contém as atividades ligadas ao uso, aprimoramento e desenho de novas ferramentas e máquinas utilizadas pela empresa no processo produtivo. Nessa função, as inovações podem ser desde uma mudança no uso de algum equipamento até no desenvolvimento de equipamentos robóticos que realizem parte do processo da obra. Cada uma dessas três funções tecnológicas é analisada em cinco níveis de capacidade tecnológica. Os dois primeiros níveis referem-se a atividades rotineiras, e os três níveis subsequentes, a atividades inovadoras.

Em cada um desses cinco níveis tecnológicos está embutido um conceito preliminar que determina as atividades que se encontram coerentes com tal definição, apresentadas a seguir:

(a) nível 1 rotineiro básico: neste nível a empresa é capaz de usar a tecnologia existente;

(b) nível 2 rotineiro avançado: neste nível são realizadas atividades que ainda utilizam a tecnologia existente, de forma plena. A empresa alcança um nível internacional na capacidade de produção, com recursos existentes. Há total controle sobre a obra, uma preocupação com o não desperdício de materiais, uso de equipamentos com desempenho superior e condições para o desenho de projetos flexíveis que venham a atender às necessidades de clientes;

(c) nível 3 inovador básico: neste nível que passa de rotineiro para inovador, a empresa já começa a ser capaz de desenvolver suas próprias inovações, tipicamente incrementais, representadas por adaptações e/ou pequenas mudanças às tecnologias existentes. As atividades passam a ser controladas por sistemas de informações gerenciais, a empresa passa a adaptar modelos originalmente concebidos em ambientes fabris, como a criação de células de trabalho;

(d) nível 4 inovador intermediário: neste nível as atividades de produção passam a ser desempenhadas de uma forma integrada e controladas por um sistema de automatização. Os projetos passam a ser desenvolvidos para a produção de obras altamente complexas, e a empresa passa a ter a capacidade de criação de seus próprios equipamentos. Inovações incrementais de maior complexidade com modificações de componentes passam a existir; e

(e) nível 5 inovador avançado: este nível corresponde ao nível de tecnologia de fronteira, no qual a empresa tem a capacidade de realizar inovações radicais, ter um centro de $\mathrm{P} \& \mathrm{D}$ em parceria com outros centros de pesquisa de nível internacional, para o desenvolvimento de novos modelos produtivos, de projetos que desenhem estruturas não usuais e de criação de equipamentos robóticos.

A seção seguinte trata das considerações finais do trabalho e das implicações do modelo. 
Amb. Const., Porto Alegre, v. 11, n. 1, p. 41-51, jan./mar. 2011.

\begin{tabular}{|c|c|c|c|}
\hline \multirow{2}{*}{ Níveis } & \multicolumn{3}{|c|}{ Funções Tecnológicas e Atividades Relacionadas } \\
\hline & Processo e Organização da Produção & Projeto & Equipamentos \\
\hline 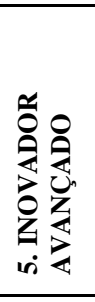 & $\begin{array}{l}\text { Desenvolvimento de novos modelos de } \\
\text { logística para construção (ex.: logística } \\
\text { reversa, consórcio modular). } \\
\text { Desenvolvimento de novos métodos de } \\
\text { planejamento (ex.: utilização de redes } \\
\text { neurais, utilização de sistemas especialistas, } \\
\text { data mining). Desenvolvimento de novos } \\
\text { processos em parceria com centros de } \\
\text { pesquisa internacionais. }\end{array}$ & $\begin{array}{l}\text { Desenho de novos modelos de estruturas não } \\
\text { usuais (ex.: abandono dos planos ortogonais, } \\
\text { estruturas espaciais não ortogonais, prédios } \\
\text { curvos). Geração de novos sistemas construtivos } \\
\text { (ex.: sistemas completos em aço, sistemas } \\
\text { completos em compósitos). Participação em redes } \\
\text { colaborativas de projeto (ex.: projetação de forma } \\
\text { colaborativa entre os integrantes da cadeia } \\
\text { produtiva). Set based design. }\end{array}$ & $\begin{array}{l}\text { Pesquisa e desenvolvimento } \\
\text { de novos equipamentos em } \\
\text { parceria com centros de } \\
\text { pesquisa. Desenvolvimento } \\
\text { de robôs e equipamentos } \\
\text { CNC (Computer Numerical } \\
\text { Controlled }) \text { para execução } \\
\text { integrada de partes da obra. }\end{array}$ \\
\hline 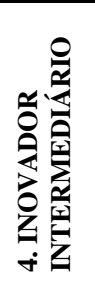 & $\begin{array}{l}\text { Gerenciamento da variabilidade } \quad \text { (ex.: } \\
\text { filosofia Seis Sigma). Integração do } \\
\text { planejamento de curto, médio e longo } \\
\text { prazos. Automatização das integrações de } \\
\text { todos os níveis do processo (ex.: sistema de } \\
\text { gerenciamento integrado). Desenvolvimento } \\
\text { de processos construtivos em parceria com } \\
\text { centros de pesquisa nacionais. }\end{array}$ & $\begin{array}{l}\text { Desenvolvimento de projetos de prédios de alta } \\
\text { complexidade (ex.: prédios inteligentes). } \\
\text { Desenvolvimento de projetos sustentáveis } \\
\text { (greenbuilding). Projeto com previsão de } \\
\text { monitoramento contínuo dos indicadores de } \\
\text { segurança (ex.: risco de explosões, desabamentos). } \\
\text { Modelagem da Informação para Construção } \\
\text { (BIN). }\end{array}$ & $\begin{array}{l}\text { Projeto e produção de novos } \\
\text { equipamentos por setor } \\
\text { específico em parceria com } \\
\text { fornecedores. }\end{array}$ \\
\hline 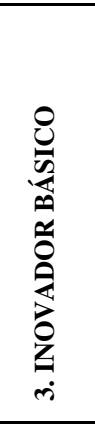 & $\begin{array}{l}\text { Melhoria contínua nos sistemas de } \\
\text { informações gerenciais. Gerenciamento de } \\
\text { controle de estoque e movimentação de } \\
\text { materiais usando um sistema central. } \\
\text { Adaptação e uso no modelo de produção } \\
\text { enxuta. Melhoria contínua nos sistemas } \\
\text { construtivos adquiridos (controle e pequenos } \\
\text { aperfeiçoamentos no sistema de drywall). } \\
\text { Estruturação do processo produtivo por } \\
\text { células de produção. }\end{array}$ & $\begin{array}{l}\text { Desenvolvimento de projetos utilizando recursos } \\
\text { construtivos avançados (ex.: aumento de vãos } \\
\text { estruturais, componentes de pesos mais leves, } \\
\text { pisos flutuantes). Desenvolvimento integrado de } \\
\text { projetos com ênfase na manutenibilidade. } \\
\text { Gerenciamento de uma rede de vários projetistas. } \\
\text { Desenvolvimento integrado de projetos com } \\
\text { ênfase na compatibilidade de sistemas } \\
\text { construtivos (ex.: forros que integrem sistemas de } \\
\text { iluminação, ar condicionado e proteção contra } \\
\text { incêndio e de isolamento acústico). } \\
\text { Desenvolvimento de projetos com o auxílio de } \\
\text { especialistas de outras áreas (ex.: sociólogos). }\end{array}$ & \begin{tabular}{|lr} 
Aprimoramentos & \\
sistemáticos & em \\
equipamentos. Gestão de \\
equipamentos \\
manutenção, prospecção, \\
aquisição e controle).
\end{tabular} \\
\hline 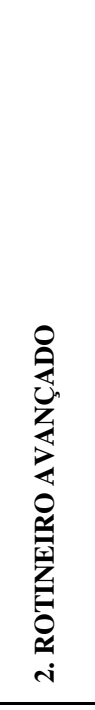 & $\begin{array}{l}\text { Utilização de um sistema de gerenciamento } \\
\text { de qualidade (ex.: certificação do PBQPH). } \\
\text { Realização dos cronogramas de atividades } \\
\text { com uso do PERT/CPM. Gerenciamento do } \\
\text { processo com base no controle orçamentário } \\
\text { e fluxo de caixa. Gerenciamento de alocação } \\
\text { sistemática de pessoal nas atividades do } \\
\text { canteiro de obra (ex.: alocação diária de mão } \\
\text { de obra, ordem de serviço diária). Utilização } \\
\text { de Sistemas de Gestáo de Resíduos (ex.: } \\
\text { PGRS). Uso de técnicas sistêmicas de } \\
\text { análise de solução de problemas (ex.: } \\
\text { MASP). Utilização de sistemas construtivos } \\
\text { para execução integrada de partes da obra } \\
\text { (ex.: sistemas de fôrmas, sistemas de de } \\
\text { cimbramentos, drywall). Avaliação de } \\
\text { desempenho in loco (ex.: testes para } \\
\text { confirmar capacidade de suporte dos } \\
\text { elementos de fundação ou teste de } \\
\text { arrancamento de revestimentos). } \\
\text { Coordenação dos trabalhos de empresas } \\
\text { terceirizadas. }\end{array}$ & $\begin{array}{l}\text { Projeto com suporte de especialistas, consultores } \\
\text { ou fornecedores. Realização sistêmica de pesquisa } \\
\text { de mercado. Aplicação de conceitos de } \\
\text { construtibilidade (ex.: desenho orientado para a } \\
\text { produção). Coordenação de projeto. }\end{array}$ & $\begin{array}{l}\text { Utilização de ferramentas } \\
\text { com desempenho superior } \\
\text { (ex. laser, bobcat). } \\
\text { Manutenção preventiva dos } \\
\text { equipamentos. }\end{array}$ \\
\hline 承 & $\begin{array}{l}\text { Utilização de controles ligados ao } \\
\text { pagamento por produção. Planejamento de } \\
\text { longo prazo. Coleta de resíduos. } \\
\text { Movimentação dos materiais segundo layout } \\
\text { planejado. Controle básico de estoque. }\end{array}$ & $\begin{array}{l}\text { Uso de soluções de projetos padronizados (ex.: } \\
\text { biblioteca de detalhes de projetos). Briefing de } \\
\text { projetos a partir de pesquisa de mercado. Projeto } \\
\text { com ênfase na compatibilidade. }\end{array}$ & $\begin{array}{l}\text { Manufatura de ferramentas } \\
\text { de baixa complexidade } \\
\text { tecnológica (ex.: pá, } \\
\text { carrinho de transporte, etc.). } \\
\text { Manutenção corretiva dos } \\
\text { equipamentos. }\end{array}$ \\
\hline
\end{tabular}

Quadro 1 - Modelo para avaliação de capacidades tecnológicas em empresas do setor de construção civil - subsetor de edificações 


\section{Considerações finais}

Estudos que tratam da gestão da inovação em empresas altamente inovadoras tomam como dado o fato de que essas empresas já possuem capacidade inovadora e que se movem próximo à fronteira tecnológica internacional. $\mathrm{O}$ foco desses estudos é na renovação de competências. Por outro lado, estudos em empresas de economias emergentes buscam elucidar de que forma empresas situadas em países em desenvolvimento constroem suas competências. $\mathrm{O}$ entendimento acerca desse processo é de extrema importância, porque revela um quadro diferente daquele que prevaleceu por um longo período, quando se entendia que as empresas emergentes estavam passivamente envolvidas somente na seleção e na adoção de tecnologias desenvolvidas em economias industrializadas.

Tendo em mente a necessidade de avaliar a acumulação de capacidades tecnológicas, e não apenas sua renovação, torna-se mister o desenvolvimento de modelos que permitam a avaliação dessa evolução e, mais do que isso, que considerem que a inovação não ocorre apenas pela geração de patentes e/ou pesquisa e desenvolvimento. É nesse sentido que se apresenta a relevância do estudo ora conduzido.

Ao identificar atividades próprias da indústria sob análise, pretende-se prover um guia para avaliação por parte dos gestores da forma a avaliar como a empresa vem evoluindo, desde atividades de produção até atividades inovadoras. Da mesma forma, os gestores podem avaliar se o processo está ocorrendo de forma cumulativa, ou seja, verificar se não ocorrem descontinuidades na acumulação e também avaliar quanto tempo (velocidade) a empresa demorou para acumular (ou deixar de acumular) capacidades em seus diversos níveis.

Conforme mencionado anteriormente, o modelo, já desenvolvido para outros setores da economia, traz uma vantagem sobre os indicadores tradicionais utilizados para mensurar a capacidade tecnológica nas empresas, como, por exemplo, gastos em P\&D e estatísticas de patentes. Tais indicadores apresentam várias limitações, entre elas o fato de que os gastos com $\mathrm{P} \& \mathrm{D}$ e a geração de patentes são medidas mais apropriadas para mensuração das capacidades tecnológicas de alguns setores industriais de economias tecnologicamente avançadas. A pesquisa desenvolvida neste estudo trata de um setor tradicional da economia que, além de não possuir níveis sofisticados de capacidade tecnológica, é essencialmente representado por pequenas e médias empresas sem recursos suficientes para gastos com P\&D. Outra vantagem no modelo proposto diante dos indicadores tradicionais é a possibilidade da análise longitudinal em detrimento das avaliações estáticas geralmente produzidas por esses indicadores.

Ao incluir diferentes níveis de evolução da capacidade tecnológica das empresas de setores tradicionais, agrega-se a possibilidade de reconhecer diferentes níveis de inovação, que vão desde a imitação de produtos/processos já existentes até a adoção de novos produtos ou processos organizacionais. A inclusão dessa perspectiva é essencial à compreensão da forma como ocorre o desenvolvimento tecnológico em economias em desenvolvimento. A medida aqui proposta identifica as atividades que as empresas são capazes de desenvolver de forma autônoma ao longo do tempo. Importante mencionar que não há um pressuposto de evolução contínua à medida que se entende que, entre as trajetórias possíveis de ser observadas, estão tanto a construção e o acúmulo de capacidades quanto a perda destas. A análise dos fatores subjacentes a esses processos é essencial ao entendimento das variáveis que conduzem à inovação.

A partir daí é possível apresentar as implicações gerenciais do estudo. A aplicação empírica do modelo proposto permite avaliar o nível tecnológico das empresas situadas em um setorchave da economia brasileira, identificar a forma e a velocidade com que certas empresas desse setor têm acumulado capacidade tecnológica, o que pode destacar casos de benchmarking de empresas líderes em inovação e recomendar políticas específicas para a construção civil, que conduzam a níveis mais elevados de capacidade um setor tão relevante da economia.

É prudente finalizar o trabalho relembrando as limitações metodológicas do estudo, que contou, para o desenvolvimento da métrica, com a colaboração de dois especialistas com atuação acadêmica nacional e internacional e de três gestores com atuação mercadológica regional, além da consulta em fontes bibliográficas específicas.

\section{Referências bibliográficas}

\author{
AMORIM, S. R. L. Políticas Tecnológicas na \\ Construção Civil Leve no Brasil: 1965-1990. Rio \\ de Janeiro, 1992.
}

AOUAD, G.; OZORHON, B.; ABBOTT, C. Facilitating innovation in Cnstruction: directions and implications for research and policy. Construction Innovation: information, process, management, v.10, n. 4, p. 374-394, 2010. 
ARO, C.; AMORIM, S. As Inovações

Tecnológicas no Processo de Produção dos Sistemas Prediais Hidráulicos e Sanitários. In: CONFERÊNCIA LATINO-AMERICANA DE CONSTRUÇÃO SUSTENTÁVEL, 1.; ENCONTRO NACIONAL DE TECNOLOGIA DO AMBIENTE CONSTRUÍDO, 10., São Paulo, 2004. Anais... São Paulo: CLACS; ENTAC, 2004. 1 CD-ROM.

BARROS, M.; SABBATINI, F. H.; FRANCO, L. S. Implantação de Inovações Tecnológicas na Produção de Edifícios. In: SIMPÓSIO DE GESTÃ̃ DA INOVAÇÃO TECNOLÓGICA, 19., São Paulo, 1996. Anais... São Paulo: ANPAD, 1996. 1 CD-ROM.

BALL, M. Chasing a Snail: innovation and housebuilding firms. Housing Studies, v.14, n.1, p. 922, 1999.

BAYER, S.; GANN, D. Innovation and the Dynamics of Capability Accumulation in ProjectBased Organizations. In: DRUID SUMMER CONFERENCE ON KNOWLEDGE, INNOVATION AND COMPETITIVENESS:

dynamics of firms, networks, regions and institutions, Copenhagen, 2006. Proceedings... Copenhagen, 2006. 1 CD-ROM.

BELL, M. Learning and the of Industrial Technological Capacity in Developing Countries. In: KING, K.; FRANSMAN, M. (Eds.). Technological Capability in the Third World. London: Macmillan, 1984.

BELL, M; PAVITT, K. The Development of Technological Capabilities. In: HAGUE, et al. Trade, Technology and International Competitiveness. Washington, DC: World Bank, 1995.

BELL, R. M.; ALBU, M. Knowledge Systems and Technological Dynamism in Industrial Clusters in Developing Countries. Word Development, v. 27, n.9, p.1715-1734, 1999.

BEN, F. Acumulação de Capacidades Tecnológicas e Suas Implicações para a Performance Corporativa: um estudo comparativo entre duas empresas da indústria moveleira em Bento Gonçalves, RS. 2001. 166 f. Dissertação (Mestrado Executivo) - Centro de Formação Acadêmica e Pesquisa, Fundação Getúlio Vargas, Rio de Janeiro, 2001.

BERNARDES, M. M. S. Planejamento e Controle da Produção para Empresas de Construção Civil. Rio de Janeiro: LTC Editora, 2003.
BÜTTENBENDER, P. Acumulação de Capacidades Tecnológicas e os Processos Subjacentes de Aprendizagem na Indústria Metal-Mecânica: o caso da empresa AGCO Comércio e Indústria Ltda em Santa Rosa, RS. 2001. 190 f. Dissertação (Mestrado Executivo) Centro de Formação Acadêmica e Pesquisa, Fundação Getúlio Vargas, Rio de Janeiro, 2001.

BRITO, K. Ligações Entre Empresas e as Demais Organizações do Sistema de Conhecimento como Fonte de Aprendizagem e Suas Implicações para o Desenvolvimento de Capacidades Tecnológicas Inovadoras: evidências de uma amostra de empresas do setor de TIC no Brasil. 2008. 205 f. Dissertação (Mestrado em Gestão de Empresas) - Fundação Getúlio Vargas, Rio de Janeiro, 2008.

CANIËLS, M. C. J.; ROMIJN, H. A. SME Clusters, Acquisition of Technological Capabilities and Development: concepts, practice and policy lessons. Journal of Industry, Competition and Trade, v.3, n.3, p.187-210, set. 2003.

CARDOSO, F. Estratégias Empresariais e Novas Formas de Racionalização da Produção no Setor de Edificações no Brasil e na França: parte 1.

Estudos Econômicos da Construção, São Paulo, v. 2, p. 97-156, 1996.

CASTRO, J. A. Invento e Inovação Tecnológica: produtos e patentes na construção. São Paulo: Annablume, 1999.

COSTA, C. Processos de aprendizagem e acumulação de capacidades tecnológicas na indústria de injeção plástica: o caso da Multibrás da Amazônia S.A. 2002. 139 f. Dissertação (Mestrado Executivo), FGV, Rio de Janeiro, 2002.

FIGUEIREDO, P. Technological Learning and Competitive Performance. Cheltenham, UK; Northhampton, US: Edward Elgar, 2001.

FIGUEIREDO, P. Acumulação Tecnológica e Acumulação Industrial: conceitos, mensuração e evidências no Brasil. São Paulo em Perspectiva, v. 19 , n. 1 , p. 54-69, 2005.

GARCIA, C. T. Evolução Setorial e Trajetórias Tecnológicas em Nível de Empresas na Indústria de Celulose e Papel no Brasil (19702004): contexto da política de substituição de importações à competição globalizada. 2006. 319 f. Dissertação (Mestrado em Administração Pública) - Fundação Getúlio Vargas, Rio de Janeiro, 2006.

HARTMANN, A. The Context of Innovation Management in Construction Firms. Construction Management and Economics, v. 24, n. 6, p. 567 578, jun. 2006. 
HEINECK, L.; MACHADO, R. A Geração de Cartões de Produção na Programação Enxuta de Curto Prazo em Obra. In: SIMPÓSIO BRASILEIRO DE GESTÃO DA QUALIDADE E ORGANIZAÇÃO DO TRABALHO NO AMBIENTE CONSTRUÍDO, 2., Fortaleza, 2001. Anais... Fortaleza: SIBRAGEQ, 2001. 1 CDROM.

KEAST, R.; HAMPSON, K. Building Constructive Innovation Networks: role of relationship management. Journal of Construction Engineering and Management, v. 133, p. 367-373, 2007.

KIM, L. Stages of Development of Industrial Technology in a Developing Country: a model. Research Policy, v. 9, n. 3, p. 254-277, 1980.

KIM, L. Imitation to Innovation: the dynamics of korea's technological learning. Boston: Harvard Business School Press, 1997.

KOSKELA, L.; VRIJHOEF, R. Is the Current Theory of Construction a Hindrance do Innovation? Building Research \& Information, v. 29, n. 3, p. 197-207, 2001.

LALL, S. Technological Capabilities and Industrialization. World Development, London, v. 20, n. 2, p. 165-186, 1992.

LU, S. L; SEXTON, M. G. Innovation in Small Construction Knowledge-Intensive Professional Service Firms: a case study of an architectural practice. Construction Management and Economics, v. 24, n. 12, p. 1269-1282, 2006.

NAM, C. M; TATUM, C. B. Major Characteristics of Constructed Products and Resulting Limitation of Construction Technology. Construction Management and Economics, v. 6, n. 2, p. 133$148,1988$.
REICHSTEIN, T.; SALTER, A.; GANN, D. Break on Through: sources and determinants of product and process innovation among UK construction firms. In: DRUID TENTH ANNIVERSARY SUMMER CONFERENCE, Copenhagen, 2005. Proceedings... Copenhagen, 2005.

RUIKAR, K.; KOSKELA, L.; SEXTON, M. Communities of Practice in Construction Case Study Organisations: questions and insights. Construction Innovation: Information, Process, Management, v. 9, n. 4, p.434- 448, 2009.

RUSH, H.; BESSANT, J.; HOBDAY, M. Assessing the Technological Capabilities of Firms: developing a policy tool. R\&D Management, $v$. 37 , n. 3, p. 221-236, 2007

SCHMITZ, H. Transitions and Trajectories in the Build-Up of Innovation Capabilities: insights form the Global Value Chain. Asian Journal of Technology Innovation, v. 15, n. 2, p. 151-160, 2007.

SLAUGHTER, S. Builders as Sources of Construction Innovation. Journal of Construction Engineering and Management, v. 119, n. 3, p. 532-549, set. 1993.

SLAUGHTER, S. Assessment of Construction Processes and Innovation Through Simulation. Construction Management and Economics, v. 17, n. 3, p. 341-350, 1999.

VALLADARES, L. P. Repensando a Habitação no Brasil. Rio de Janeiro: Zahar Editores, 1983.

VARGAS, N. Organização do Trabalho e Capital: estudo da construção habitacional. Dissertação (Mestrado em Engenharia Civil) Programa de Pós-graduação de Engenharia, Universidade Federal do Rio de Janeiro, 1979.

Revista Ambiente Construído

Associação Nacional de Tecnologia do Ambiente Construído

Av. Osvaldo Aranha, $99-3^{\circ}$ andar, Centro

Porto Alegre - RS - Brasil CEP $90035-190$

Telefone: +55 (51) 3308-4084

Fax: +55 (51) 3308-4054

www.seer.ufrgs.br/ambienteconstruido

E-mail: ambienteconstruido@ufrgs.br 